\title{
Tem Ideia na Rede: Inserindo o Pensamento Computacional na Rede Municipal de Ensino
}

\author{
André Luiz Maciel Santana ${ }^{1}$, Elieser Ademir de Jesus ${ }^{1}$, Larissa Aparecida Cucco', \\ Luís Felipe Maciel Santana ${ }^{14}$, André Luís Alice. Raabe ${ }^{123}$, Gustavo L. Ramos ${ }^{1}$ \\ ${ }^{1}$ Laboratório de Inovação Tecnológica na Educação - CTTMar - UNIVALI \\ ${ }^{2}$ Programa de Pós-Graduação em Educação \\ ${ }^{3}$ Mestrado em Computação Aplicada \\ ${ }^{4}$ Curso de Arquitetura e Urbanismo \\ andrelms@univali.br, raabe@univali.br, lite@univali.br
}

\begin{abstract}
This Experience Report shows the main results about Tem Ideia na Rede, that has engaged around of 209 students from $5^{\circ}$ to $9^{\circ}$ class of Brazilian Primary School of 28 public schools. Additionally, the event reaches 24 educators from Informatics and 10 teachers from subjects such as Geography, Mathematics, English, and Science. The results indicate that programming could be applied to Primary School and tools such as Social Networks (Facebook, WhatsApp, and Youtube) may help it. Furthermore, the evaluation process must be attentive to the engagement and necessity encourage personal projects. In addition, the most important criteria are the path from the idea conception to the implementation. As result for the community, that event will be integrated with the Scholar Calendar.
\end{abstract}

Resumo. Este relato de experiência apresenta os principais resultados do Tem Ideia na Rede, um evento que promoveu a aprendizagem de computação e programação com 209 estudantes de $5^{\circ}$ ao $9^{\circ}$ ano (reunidos em equipes) em 28 escolas da rede pública. $\mathrm{O}$ evento integrou 24 instrutores de informática e cerca de 10 professores de disciplinas como matemática, ciências, geografia, inglês e etc, que atuaram como mediadores do processo. Os resultados indicam que conceitos de programação podem ser abordados no Ensino Fundamental II e que o uso de ferramentas como Facebook, Youtube e Whatsapp auxiliam este processo. Além disso, durante a avaliação ficou claro que os principais ganhos de aprendizagem ocorrem quando os estudantes se sentem motivados com seu projeto e que o processo de avaliação deve valorizar a trajetória e evolução de cada equipe. Como resultados para comunidade, o evento passou a integrar o calendário escolar da cidade.

\section{Introdução}

Como premissa para a educação do século XXI, várias iniciativas têm sido fomentadas com o objetivo de viabilizar uma formação acadêmica mais plena e capaz de contribuir 
com o desenvolvimento do ser humano como cidadão pertencente à uma sociedade moderna. Estas iniciativas são desenvolvidas com enfoques que tratam desde a produção de objetos de aprendizagem e artefatos tecnológicos (BEERS, 2014; RAABE et al, 2015; SANTANA et al 2016) até a elaboração de metodologias de ensino e de construção do conhecimento. (VALENTE, 1993; RESNICK, 2002; WING, 2006; PAPERT, 2008).

Desde as definiçõoes de Wing (2006) para o Pensamento Computacional, muito se discute sobre o papel da Computação na formação acadêmica e como o empoderamento tecnológico pode contribuir como habilidade para formação do ser humano. Blikstein (2008) aborda este tema ao tratar o Pensamento Computacional como uma habilidade capaz de potencializar o exercício da cidadania no século XXI através do desenvolvimento da capacidade criativa, inventiva e produtiva.

Os trabalhos supracitados tratam de estratégias que fomentam a aprendizagem centrada no estudante (BURD, 1999), assumindo que os papéis de educador e educando não estão restritos a instrutor e ouvinte. Estas abordagens retomam conceitos já presentes nas ideias de Papert (2008) que tratam do Construcionismo, uma visão de educação focada no estudante e que tende a valorizar a aprendizagem por meio da experimentação e da percepção de erros e acertos.

Neste contexto, o projeto busca de alguma forma inserir o Pensamento Computacional na formação de estudantes do ensino Fundamental II quando expostos a práticas extra curriculares que envolvem o uso de tecnologia. As discussões apresentadas neste artigo são oriundas dos resultados de um evento educacional chamado Tem Ideia na Rede, realizado em 2016. O evento é uma feira de ciências com viés tecnológico, e levou a aprendizagem criativa para alunos das escolas municipais em Itajaí, Santa Catarina. Durante três meses 209 estudantes do $5^{\circ}$ ao $9^{\circ}$ ano de 28 escolas utilizaram a ferramenta Scratch para desenvolver projetos em equipes de até cinco integrantes (equipes mistas com alunos entre o $5^{\circ}$ e o $9^{\circ}$ ano). Todas as equipes tiveram o apoio de um Instrutor de Informática e algumas contaram com o apoio de um(a) professor(a) de área (Matemática, Ciências, Língua Portuguesa, etc.).

Durante os três meses de atividades os projetos realizados pelos estudantes foram registrados através de vídeos que foram analisados e discutidos pelos organizadores do evento. Ao final as equipes apresentaram seus trabalhos em uma feira (realizada em novembro de 2016). Neste artigo são analisados os resultados deste evento com o objetivo de compartilhar as experiências vivenciadas e demonstrar a viabilidade da inserção do Pensamento Computacional nas atividades escolares, especialmente com os estudantes do ensino Fundamental II.

Nas seções 2 e 3, respectivamente, são discutidas as metodologias utilizadas e os resultados obtidos. Na seção 4 são apresentados pareceres acerca das produções criadas durante o evento, tal como, uma análise de resultados a partir de rubricas especificadas durante a concepção do evento. Por fim, a seção 5 apresenta as conclusões e sugestões de melhorias e alterações planejadas para as edições futuras do evento.

\section{Metodologia do Evento}

O Tem Idéia na Rede é um evento educacional com foco nos estudantes do $5^{\circ}$ ao 
$9^{\circ}$ ano do ensino fundamental da rede municipal de Itajaí, Santa Catarina (SC). Ao longo de 3 meses os estudantes tiveram contato com a computação de forma prática e criativa.

O nome do evento faz referência à rede de pesca, já que a cidade de Itajaí - SC tem uma forte cultura pesqueira. Além disso, a palavra rede também remete a outras duas ideias: a internet e a rede de pessoas interconectadas compartilhando conhecimento durante o evento.

O Scratch foi escolhido como principal ferramenta para o evento por simplificar o ato de programar, permitindo criar aplicações relativamente complexas com pouco ou nenhum conhecimento prévio na área, e por também ser disponibilizado em português (diminuindo a barreira do idioma na aprendizagem de programação).

$\mathrm{Na}$ cidade de Itajaí, SC, quase todas as escolas municipais possuem laboratório de informática dirigido por um Instrutor, que é um profissional concursado no município e geralmente graduado (ou graduando) em Computação ou áreas afins. Em 2016 o município de Itajaí promoveu cursos capacitantes para estes Instrutores de Informática, incluindo capacitação para uso do Scratch. Além disso, no período pré evento (durante as inscrições) foram realizados encontros com os Instrutores a fim de relembrar funcionalidades do Scratch, sanar dúvidas e compartilhar experiências.

\subsection{Cronologia}

O evento iniciou oficialmente com uma reunião envolvendo todos os gestores das escolas municipais onde foram apresentados os detalhes tais como a concepção, os objetivos, o cronograma, etc. Esta reunião foi um importante marco para o evento, onde os gestores foram convocados à abraçar a causa, disseminando a ideia para os demais profissionais das suas escolas (professores e instrutores).

O Tem Ideia na Rede durou três meses, divididos em período de inscrição (aproximadamente um mês), desenvolvimento dos projetos e feira de apresentação dos trabalhos realizados. As inscrições foram feitas através do envio de um vídeo onde cada equipe se apresentou e descreveu o projeto que seria realizado. A inscrição em forma de "envio de um vídeo" foi escolhida para desburocratizar o processo e torná-lo amigável para os estudantes. Os temas dos projetos podiam ser escolhidos pelos estudantes, mas os critérios de avaliação valorizavam temas do cotidiano dos estudantes que pudessem ter algum impacto social.

Durante a fase de desenvolvimento dos projetos os estudantes reuniram-se (geralmente uma vez por semana) nos laboratórios de informática das escolas, sob a supervisão do instrutor. Boa parte das equipes se reuniram no período chamado de contra-turno, onde os estudantes fazem suas tarefas escolares e desenvolvem atividades extra curriculares. Houve relatos de equipes que trabalharam a distância e reuniram-se mais de uma vez por semana.

Durante o desenvolvimento dos projetos as equipes enviaram três vídeos de acompanhamento mostrando o que já haviam realizado e apontando dificuldades encontradas até aquele momento. Um grupo de bolsistas (estudantes de graduação) ficou encarregado de assistir estes vídeos (72 vídeos no total) e dar um feedback para 
cada equipe. Este feedback também foi feito em forma de vídeo, e este método foi escolhido para tentar humanizar o processo de avaliação, evitando a formalidade do texto, especialmente quando se trata de apresentar críticas aos trabalhos realizados. Além do feedback por meio de vídeos, alguns bolsistas visitaram as escolas mais próximas, tendo um contato direto com os estudantes e estabelecendo uma interessante troca entre estudantes universitários e estudantes do ensino fundamental II.

\subsection{Socialização e Avaliação dos Projetos Realizados}

Os projetos desenvolvidos pelos estudantes foram socializados em uma feira de apresentação realizada na sede da Secretaria Municipal de Educação (SME). Durante uma tarde os estudantes apresentaram seus trabalhos para uma banca avaliadora e para os demais presentes. O grupo de avaliadores foi formado por 9 pessoas, incluindo professores, gestores da educação e empresários de tecnologia da região.

O trabalho de cada equipe foi avaliado por 3 pessoas considerando os critérios de engenhosidade da solução, engajamento da equipe, interdisciplinaridade, coerência da solução e impacto na comunidade. Estes critérios de avaliação foram concebidos com o objetivo de valorizar a trajetória dos estudantes ao longo do evento, promover interdisciplinaridade, e fomentar o engajamento e a autonomia dos participantes.

\section{Resultados Obtidos}

Nesta seção são discutidos os resultados qualitativos e quantitativos do Tem Ideia na Rede. Os resultados qualitativos refletem a percepção das pessoas envolvidas sobre impacto gerado na vida (e não apenas na aprendizagem) dos estudantes. O evento contou com a participação de 28 escolas municipais, envolvendo 209 estudantes, 24 Instrutores de Informática e 10 professores de disciplinas curriculares. Apresenta-se também resultados gerados pela ferramenta Dr. Scratch, onde os projetos dos estudantes foram analisados para mensurar habilidades que são desenvolvidas à medida que se estimula o Pensamento Computacional.

\subsection{Diminuindo a Distância entre a Escola e o Cotidiano dos Estudantes}

Na fase de planejamento do Tem Ideia na Rede cogitou-se que a inscrição das equipes aconteceria através da postagem de um resumo de cada projeto. De fato, cada equipe postou um resumo da sua ideia, mas este resumo não foi textual (como de costume). Cada equipe postou um vídeo filmado com um telefone celular. Inúmeras nuances (sorrisos, nervosismo, timidez) que não seria possível transmitir em um texto resumido foram transmitidas através do vídeo. Ao permitir que os alunos gravassem vídeos (ao invés de escreverem textos) foi criado um canal de comunicação bastante rico em termos de expressividade.

Alguns professores e instrutores de informática levaram os alunos para fora da escola (parques, praças, etc.) e gravaram vídeos divertidos e descontraídos. Estes professores transformaram algo que poderia ser muito tradicional e "sem graça" (postar o resumo da ideia do projeto) em uma atividade que envolveu a saída do ambiente escolar, o planejamento do conteúdo do vídeo, a escolha de um cenário (a praça, o 
VI Congresso Brasileiro de Informática na Educação (CBIE 2017)

Anais do XXIII Workshop de Informática na Escola (WIE 2017)

parque) e de um ângulo ideal para filmar. Além disso, cabe ressaltar que estas filmagens utilizaram uma ferramenta que está muito presente na realidade da maioria dos alunos (o telefone celular), diminuindo a distância entre a escola e a realidade cotidiana.

\subsection{Quebrando o Paradigma da Seriação}

Outro resultado que convém destacar são as equipes mistas, onde estudantes de diferentes anos (do $5^{\circ}$ ao $9^{\circ}$ ) puderam se organizar em grupos de trabalho. Entendemos que isto é um avanço em relação ao modo como os estudantes tradicionalmente são agrupados nas escolas (por idade), já que estudantes com a mesma idade podem apresentar níveis muito diferentes de maturidade intelectual. Além disso, quando as turmas são formadas, é possível que estudantes que possuem afinidade não possam trabalhar juntos se estiverem matriculados em turmas diferentes. $\mathrm{O}$ agrupamento por idade também diminui as chances de que estudantes mais jovens (porém intelectualmente maduros) convivam e aprendam com os de mais idade, e de que, no sentido oposto, os mais jovens possam ensinar algo para os mais velhos.

Ao possibilitar que alunos de diferentes turmas e idades formassem equipes o Tem Ideia na Rede quebrou a lógica tradicional de seriação (tão comum em nossas escolas), permitindo que os grupos fossem formados por afinidade, com os próprios alunos negociando e escolhendo seus pares.

\subsection{Uso de Redes Sociais e outras Ferramentas de Comunicação}

Juntamente com o Instrutor de Informática algumas equipes criaram grupos secretos no facebook. Durante a feira de apresentação mostraram as discussões realizadas, além de desenhos e esboços compartilhados através da ferramenta.

Os instrutores de informática utilizaram um grupo no aplicativo Whatsapp para entrar em contato com os organizadores do evento e para comunicarem-se entre si. Também foram criadas várias salas de bate-papo (uma para cada escola) na ferramenta Google Hangouts para possibilitar que os estudantes entrassem em contato diretamente com os bolsistas (estudantes de graduação). Entretanto, somente os instrutores usaram estas salas para tirar dúvidas sobre envio de materiais e cronograma. Acreditamos que isto se deu por conta do pouco tempo semanal que as equipes dispunham para usar os laboratórios de informática nas escolas.

Além disso, no início do evento foram avaliadas redes sociais para compartilhamento de experiências rápidas entre os estudantes e a equipe de organização do evento. Neste sentido, foi avaliado o uso da rede social Snapchat que acabou não demonstrando efetividade para o público-alvo escolhido. Para suprir esta demanda e concentrar as informações em um único canal de informação, foram definidas como redes sociais para este propósito o Youtube e o Facebook. A primeira viabilizou concentrar todo o material em um único repositório e a segunda possibilitou compartilhar estes resultados.

\subsection{A Importância de Socializar as Produções}


Alguns estudantes comentaram que não esperavam ver tantas pessoas reunidas na feira de apresentação (ver Figura 1), pois achavam que seria algo pequeno, focado unicamente em "dar nota" para os trabalhos realizados. Ao ver tanta gente reunida os estudantes imediatamente perceberam a importância das suas produções. Além de apresentar os trabalhos para os avaliadores os estudantes também apresentaram para outras equipes, gerando uma enriquecedora troca de experiências entre os participantes.
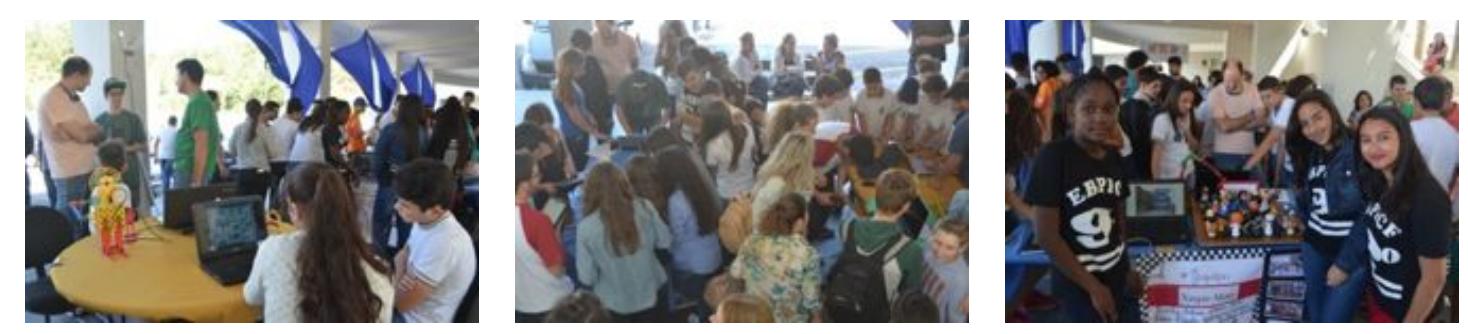

Figura 1. Feira de Apresentações

Outro resultado percebido durante a feira de apresentação foi a reação de alguns pais ao verem seus filhos defendendo os projetos. Sempre que uma comissão de avaliação (composta por 3 pessoas) se aproximava os pais percebiam (pela postura e linguagem corporal dos filhos) que aquele era um momento importante, e que o trabalho realizado pelos filhos tinha significado. Os pais não se manifestaram verbalmente durante as apresentações dos seus filhos, mas seus sorrisos e brilho nos olhos não deixavam dúvidas sobre o orgulho vivenciado naquele momento.

\subsection{O Papel dos Instrutores de Informática}

Parte do resultado positivo do Tem Ideia na Rede se deve a atuação dos Instrutores de Informática das escolas municipais. Estes profissionais organizaram as equipes e conduziram os trabalhos com os estudantes, seja motivando ou auxiliando na resolução de problemas mais difíceis. No início do evento foi realizada uma reunião com estes instrutores para comunicar que eles deveriam atuar como mediadores, sempre incentivando a autonomia dos alunos, além de auxiliarem nas questões mais técnicas para envio de vídeos e outros materiais, comunicação com a organização do evento, etc.

Percebemos que alguns instrutores realizaram muito bem este trabalho, apenas encaminhando os alunos, mostrando possibilidades e incentivando a pesquisa. Já outros, talvez menos experientes, direcionaram demais o processo. Ao final do evento algumas equipes haviam produzido dois trabalhos: um que refletia os gostos pessoais dos estudantes e outro feito sob medida para o evento.

Um dos episódios mais marcantes neste aspecto aconteceu quando uma equipe estava animada mostrando um jogo de luta criado por eles mesmos. Quando os avaliadores chegavam o jogo era fechado e os estudantes apresentavam o outro projeto, um jogo feito para atender os critérios formais de avaliação do evento e que não parecia satisfazê-los. Em outros casos percebemos que todas as equipes de uma escola tinham trabalhado exatamente o mesmo tema, deixando a impressão de que as ideias não teriam partido dos estudantes, neste caso. 
VI Congresso Brasileiro de Informática na Educação (CBIE 2017)

Anais do XXIII Workshop de Informática na Escola (WIE 2017)

\subsection{Parceria entre Universidade, Poder Público e Iniciativa Privada}

O Tem Ideia na Rede surgiu de uma parceria entre a Universidade, a Secretaria Municipal de Educação (SME) e o Núcleo de Tecnologia da Informação e Comunicação (NuTIC) da Associação Empresarial de Itajaí.

A concepção do evento surgiu dentro da Universidade por meio de professores entusiastas. Sem a parceria com a SME não seria possível mobilizar os professores, gestores e instrutores de informática das escolas municipais. Já a premiação do evento (tablets) veio de doações feitas por empresários da região.

É fundamental ressaltar que estes três elos (Universidade, SME e NuTIC) foram fundamentais para o sucesso do Tem Ideia na Rede. A universidade por si só não tem acesso a toda a realidade e estrutura das escolas municipais. Graças a parceria com a SME o evento alcançou quase todas as escolas municipais que possuíam laboratório de informática. Por fim, não havia verba para a realização do evento, o que tornou indispensável a participação dos empresários da região para premiar os participantes.

\subsection{Avaliação dos Projetos}

Após a feira, todos os projetos criados pelos estudantes foram analisados de duas formas: (i) pelas rubricas definidas na concepção do evento e (ii) pela ferramenta Doctor Scratch.

A Figura 2 apresenta os resultados gerais de avaliação das equipes, pela abordagem das rubricas. Neste processo foram calculadas as médias de cada uma das categorias de avaliação, com pontuações de 1 a 5 e que tiveram como apoio questionamentos como: (Interdisciplinaridade) O projeto tem começo, meio e fim? Funciona? A experiência de uso faz sentido? É mais que apenas um protótipo? (Impacto na Comunidade) $O$ projeto possui algum objetivo social? Trabalha alguma temática social? Afeta algum público-alvo? Como este projeto afeta as pessoas para qual foi projetado.

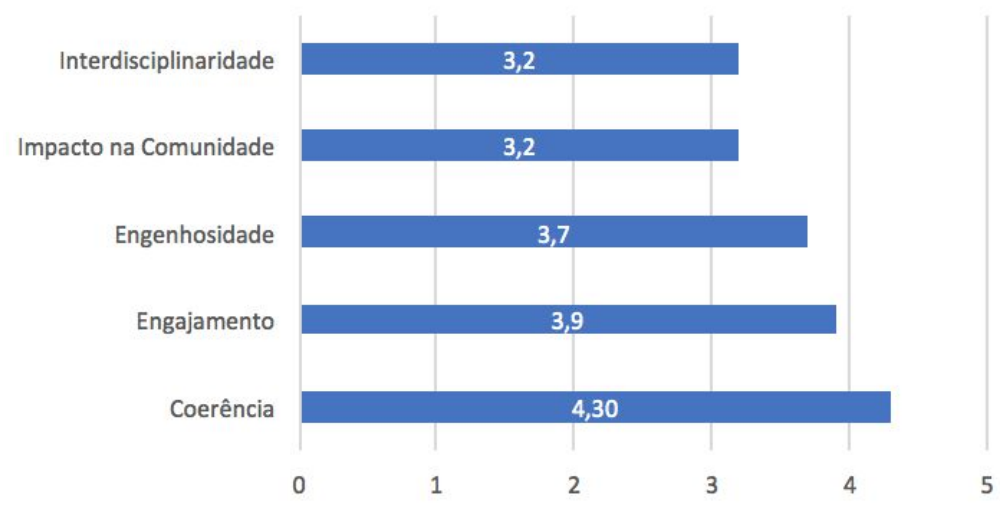

Figura 2. Resultados pela Abordagem de Rubricas

Os resultados permitiram verificar que todas as equipes que participaram da feira contemplaram de forma satisfatória os objetivos do evento, no entanto, as rubricas de Interdisciplinaridade e Impacto na Comunidade, que estão diretamente relacionadas a 
VI Congresso Brasileiro de Informática na Educação (CBIE 2017)

Anais do XXIII Workshop de Informática na Escola (WIE 2017)

motivações pedagógicas, foram as que apresentaram médias mais baixas entre as equipes participantes.

Já a ferramenta Doctor Scrach, permite avaliar os projetos por meio de categorias relacionadas à codificação, como: lógica, paralelismo, interatividade com o usuário, representação de dados, controle de fluxo, sincronização e abstração. As categorias recebem uma pontuação que pode oscilar de zero até três estrelas e que são determinadas pela quantidade de blocos relacionados com cada categoria.

Os dados gerados pelo Doctor Scratch podem ser verificados na Tabela 1 e representam o percentual de projetos que alcançaram cada uma das categorias analisadas.

\begin{tabular}{|l|c|c|c|c|}
\hline Categorias & Sem Estrelas & $*$ & $* *$ & $* * *$ \\
\hline Controle de fluxo & $0,5 \%$ & $28,1 \%$ & $\mathbf{7 1 , 4 \%}$ & $0 \%$ \\
\hline Interatividade com o usuário & $0 \%$ & $22,7 \%$ & $\mathbf{7 7 , 3 \%}$ & $0 \%$ \\
\hline Representação de dados & $6,3 \%$ & $40,6 \%$ & $\mathbf{5 3 , 1 \%}$ & $0 \%$ \\
\hline Sincronização & $20 \%$ & $35 \%$ & $\mathbf{4 5 \%}$ & $0 \%$ \\
\hline Lógica & $19,6 \%$ & $12,5 \%$ & $0 \%$ & $\mathbf{6 7 , 9 \%}$ \\
\hline Paralelismo & $8 \%$ & $16 \%$ & $0 \%$ & $\mathbf{7 6 \%}$ \\
\hline Abstração & $7,2 \%$ & $23,7 \%$ & $0 \%$ & $\mathbf{6 9 , 1 \%}$ \\
\hline
\end{tabular}

Tabela 1. Resultados pela Abordagem Doctor Scratch

Os resultados indicam que as categorias com resultados mais baixos tratam da sincronização, representação de dados, controle de fluxo e interatividade com o usuário. Essas categorias têm em comum a interação do ator com algum elemento, sendo este o usuário ou o próprio cenário em que ele se encontra. Já as categorias com maior pontuação foram as de lógica, paralelismo e abstração, que tratam dos blocos que sincronizam ações, além da capacidade de fragmentação do código.

O processo de avaliação do Doctor Scratch considera aspectos como uso de variáveis e de estruturas básicas de programação, não permitindo observar o progresso dos estudantes ao longo do desenvolvimento e nem seu amadurecimento durante o percurso.

Ao relacionar os conceitos apresentados na literatura por Blikstein (2008) e Wing (2006) e os dados indicados na Tabela 1, é possível verificar que tanto o desenvolvimento do raciocínio lógico e a capacidade de abstração foram abordados em algum grau pelos estudantes que participaram do evento. Estas habilidades são indicadas na literatura como pertencentes ao Pensamento Computacional e de alguma forma foram estimuladas ao longo do evento. Além disso, conceitos apresentados por Resnick (2007) a respeito de uma aprendizagem mais criativa, foram vivenciados pelos 
VI Congresso Brasileiro de Informática na Educação (CBIE 2017)

Anais do XXIII Workshop de Informática na Escola (WIE 2017)

estudantes quando acompanhada sua trajetória ao longo de suas produções, nesta perspectiva os estudantes foram encorajados quanto ao desenvolvimento de projetos pessoais, verificando a coerência de suas produções, seu envolvimento ao longo do evento pelas produções dos vídeos e os artefatos produzidos.

\section{Conclusões}

No evento Tem Ideia na Rede várias tecnologias foram utilizadas, tais como vídeos (gravados com telefones celulares) para reportar o progresso dos trabalhos realizados, o uso de vídeos para dar feedback aos estudantes (usando Youtube como plataforma), o uso do Facebook, Whatsapp e Google Hangouts. O uso de tecnologias tão presentes na vida de estudantes e professores aproxima a educação da realidade cotidiana e mostra o potencial destas ferramentas para possibilitar trabalho colaborativo.

A forma como o evento foi organizado (equipes mistas) e o uso das tecnologias colaborativas possibilitou a quebra da seriação escolar, criando um cenário onde estudantes de diferentes idades e turmas puderam trabalhar com propósitos em comum.

Em um depoimento em vídeo (enviado após a feira) uma estudante mencionou como o trabalho desenvolvido com a equipe tinha lhe ajudado a aceitar as ideias alheias, a expor suas ideias, a negociar com os demais, a escolher as palavras na hora de fazer críticas. Este resultado mostra como o trabalho em equipe pode fomentar $o$ desenvolvimento de habilidades que vão muito além do conteúdo curricular e que valem para toda a vida.

Observou-se que algumas equipes tiveram seus trabalhos demasiadamente direcionados (por instrutores, professores ou mesmo gestores das escolas). Idealmente os alunos seriam protagonistas e os demais envolvidos atuariam como mediadores, mas é necessário considerar que esta mudança de paradigma não pode ser alcançada repentinamente. Um dos grandes papéis do Tem Ideia na Rede é gradativamente empoderar os estudantes, o que implica repensar o papel dos demais envolvidos.

A apresentação pública dos trabalhos foi um dos grandes acertos do evento, possibilitando a socialização com os presentes e transformando o que poderia ser apenas a avaliação fria de mais um "trabalho de escola" em um ritual (incluindo um coffee break), envolvendo pais, empresários da região, estudantes, professores, instrutores de informática e gestores das escolas.

A avaliação por meio do Doctor Scratch trata de conceitos que são importantes dentro da cultura da Ciência da Computação, no entanto, não permitem avaliar a evolução dos estudantes e sua trajetória. Deste modo, sugere-se que o processo de avaliação valorize as atividades que os estudantes desenvolvem, dando maior atenção a produções como: esboços, desenhos, rascunhos de ideias, encontros para construir o trabalho, envolvimento de seus familiares e como utilizar a tecnologia para viabilizar seus projetos.

As parcerias estabelecidas possibilitaram uma maior abrangência e um impacto social relevante na comunidade, capilarizando a inserção do Pensamento Computacional na rede municipal de ensino ao levar estas ideias simultaneamente para muitas escolas. Entendemos que um outro resultado relevante é a mudança de 
VI Congresso Brasileiro de Informática na Educação (CBIE 2017)

Anais do XXIII Workshop de Informática na Escola (WIE 2017)

mentalidade dos participantes no sentido de enxergar o valor da aprendizagem baseada em projetos práticos, onde os estudantes podem atuar como protagonistas sob a mediação dos educadores.

Acreditamos que a grande lição aprendida e que pode ser aproveitada em outros lugares do Brasil é: fica mais fácil quando articulamos diferentes setores da sociedade. Ao fazer isso envolvemos mais pessoas em projetos educacionais, fazendo com que se sintam co-responsáveis pela qualidade da educação da sua região. É necessário gradativamente abandonar a ideia já enraizada de que a educação é problema dos educadores em direção a uma concepção em que a educação é um projeto de todos.

\section{Aspectos Éticos}

Todas os estudantes e professores retratados neste artigo autorizaram por escrito previamente o uso das imagens para fins de divulgação científica do projeto.

\section{Referências}

BERS, M. U. et al. Computational thinking and tinkering: Exploration of an early childhood robotics curriculum. Computers \& Education, v. 72, p. 145-157, 2014.

BLIKSTEIN, P. O pensamento computacional e a reinvenção do computador na educação. 2008. Disponível: https://goo.gl/XvCSww

BURD, Leo. Desenvolvimento de Software para Atividades Educacionais. 1999. 225 f. Dissertação (Mestrado) - Curso de Engenharia Elétrica e de Computação, Engenharia de Computação e Automação Industrial, Universidade Estadual de Campinas, Campinas, 1999.

PAPERT, Seymour. A máquina das crianças: repensando a escola na era da informática. Porto Alegre: ARTMED, 2008. 216 p.

RAABE, André et al. Brinquedos de Programar na Educação Infantil: Um estudo de Caso. In: Anais do Workshop de Informática na Escola. 2015. p. 42.

RESNICK, Mitchel. Rethinking learning in the digital age. 2002. Disponível: http://www.caribbeanelections.com/eDocs/development_reports/gitr_2001_2002.pdf \#page $=48$

RESNICK, Mitchel. All I really need to know (about creative thinking) I learned (by studying how children learn) in kindergarten. In: Proceedings of the 6th ACM SIGCHI conference on Creativity \& cognition. ACM, 2007. p. 1-6.

SANTANA, A. M., Raabe, A., Santana, L., Ramos, G., Vieira, M. V., \& dos Santos, A. A. Lite Maker: Um Fab Lab móvel para aplicação de atividades mão na massa com estudantes do ensino básico. In: Anais do Workshop de Informática na Escola. 2016. p. 211.

VALENTE, J. A. et al. Diferentes usos do computador na educação. Computadores e Conhecimento: repensando a educação, p. 1-28, 1993

WING, J. M. Computational thinking. Communications of the ACM, v. 49, n. 3, p. 33, 2006. 